\title{
PENDUGAAN FUNGSI INTENSITAS PROSES POISSON PERIODIK DENGAN TREN FUNGSI PANGKAT MENGGUNAKAN METODE TIPE KERNEL
}

\author{
Ro'fah Nur Rachmawati \\ Jurusan Matematika, Fakultas Sains dan Teknologi, Binus University \\ Jl. KH. Syahdan No. 9, Palmerah, Jakarta Barat 11480. \\ rofah.nr@binus.ac.id
}

\begin{abstract}
Stochastic process has an important role in many areas in everyday life, including the customer service process. The number of customers who come to a service center will be different for each particular time. A special form of stochastic process with continuous time and discrete state space is periodic Poisson process, which is a Poisson process with an intensity function of a periodic function. However, on the stochastic modeling of a phenomenon by a periodic Poisson process, the intensity function of the process is generally unknown. Therefore, a method is needed to infer the function. In this article, a Kernel estimator is formulated from a periodic Poisson process with a trend component in a rank function, which is divided into two cases; the identified rank function coefficient and the unidentified rank function coefficient.
\end{abstract}

Keywords: stochastic process, periodic Poisson process, Kernel function, rank function trend

\begin{abstract}
ABSTRAK
Proses stokastik memiliki peranan yang penting dalam berbagai bidang pada kehidupan sehari-hari, diantaranya pada proses pelayanan pelanggan. Banyaknya pelanggan yang datang pada suatu pusat servis akan berbeda untuk setiap waktu tertentu. Salah satu bentuk khusus dari proses stokastik dengan waktu kontinu dan ruang state diskret adalah proses Poisson periodik yaitu proses Poisson dengan fungsi intensitas berupa fungsi periodik. Namun pada pemodelan stokastik dari suatu fenomena yang dimodelkan dengan suatu proses Poisson periodik, fungsi intensitas dari proses tersebut umumnya tidak diketahui. Sehingga diperlukan suatu metode untuk menduga fungsi tersebut. Pada tulisan ini dirumuskan suatu penduga tipe Kernel dari suatu proses Poisson periodik dengan suatu komponen tren berbentuk fungsi pangkat, yang dibagi menjadi dua kasus, yaitu pada kasus pertama diasumsikan koefisien fungsi pangkat diketahui dan kasus kedua diasumsikan koefisien fungsi pangkat tidak diketahui.
\end{abstract}

Kata kunci: Proses Stokastik, Proses Poisson Periodik, Fungsi Kernel, Tren Fungsi Pangkat 


\section{PENDAHULUAN}

Pemodelan stokastik melibatkan unsur peluang untuk menduga perilaku dari suatu sistem yang tidak diketahui dengan pasti pada masa yang akan datang. Sebagai contoh, banyaknya kendaraan yang melewati suatu ruas jalan raya akan berbeda untuk setiap waktu tertentu, dalam fenomena pelayanan pelanggan (costumer service) yaitu banyaknya pelanggan yang datang ke suatu pusat servis akan berbeda untuk setiap waktu tertentu. Salah satu proses stokastik yang menarik untuk dipelajari adalah proses Poisson Periodik, yaitu suatu proses Poisson dengan fungsi intensitas berupa fungsi periodik. Namun, pemodelan suatu fenomena yang dimodelkan dengan suatu proses Poisson periodik, fungsi intensitas dari proses tersebut umumnya tidak diketahui, sehingga diperlukan suatu metode untuk menduga fungsi tersebut. Tulisan ini mengkaji pendugaan tipe Kernel proses Poisson periodik yang memiliki peranan penting dalam berbagai bidang pada kehidupan sehari-hari.

Pendugaan fungsi intensitas proses Poisson periodik tanpa melibatkan suatu komponen tren telah dilakukan kajiannya pada Mangku (2006), dan pendugaan dengan melibatkan suatu komponen tren linear telah dilakukan kajiannya pada Rachmawati (2008). Namun, jika fungsi intensitas pada proses Poisson periodik meningkat berdasarkan suatu fungsi pangkat terhadap waktu, model yang lebih tepat untuk digunakan adalah proses Poisson periodik dengan suatu komponen tren berbentuk fungsi pangkat. Dalam tulisan ini, pendugaan fungsi intensitas proses Poisson periodik dibagi menjadi dua kasus, yaitu untuk koefisien fungsi pangkat diketahui dan untuk koefisien fungsi pangkat yang tidak diketahui. Sehingga karya ilmiah ini bertujuan untuk menduga fungsi intensitas (lokal) $\lambda$ di suatu titik $s \in[0, n]$, dengan menggunakan sebuah realisasi tunggal $N(\omega)$ dari proses Poisson periodik $N$ pada $[0, n]$ (Mangku, 2006: 1) bagi kedua kasus.

\section{METODE}

Metode yang digunakan adalah studi pustaka, dengan dasar teori sebagai berikut: Misalkan $\left\{X_{1}, X_{2}, \ldots, X_{n}\right\}$ adalah peubah acak dalam ruang peluang $(\Omega, \mathcal{F}, P)$. Dikatakan bahwa barisan peubah acak $X_{n}$ konvergen dalam peluang ke $X$, dinotasikan $X_{n} \rightarrow X$, jika untuk setiap $\varepsilon>0, \mathrm{P}\left(\left|X_{n}-X\right|>\right.$ $\varepsilon) \rightarrow 0$ untuk $n \rightarrow \infty$. (Grimmet and Stirzaker, 1992, p.274).

Suatu statistik $U\left(X_{1}, X_{2}, \ldots, X_{n}\right)$ yang konvergen dalam peluang ke parameter $g(\theta)$, yaitu disebut penduga konsisten bagi $g(\theta)$ (Hogg et al., 2005, p.204)

Jika $X$ adalah peubah acak, maka untuk suatu $t>0$,

$$
\mathrm{P}=(|X| \geq t) \leq \frac{\mathrm{E}(|X|)}{t} \text {. (Ghahramani, 2005, p.476). }
$$

Jika $X$ adalah peubah acak dengan nilai harapan $\mu$ dan ragam $\sigma^{2}$, untuk setiap

$$
t>0, \mathrm{P}(|X-\mu| \geq t) \leq \frac{\sigma^{2}}{t^{2}} \text {. (Ghahramani, 2005, p.477). }
$$

Suatu titik $s$ disebut titik Lebesgue dari suatu fungsi $\lambda$ yang terintegralkan lokal, jika

$$
\lim _{h \rightarrow 0} \frac{1}{2 h} \int_{-h}^{h}|\lambda(x+s)-\lambda(s)| d x=0 \text {. (Wheeden RL, Zygmund A. 1997, p.239). }
$$

Pendugaan fungsi intensitas proses Poisson periodik tanpa menggunakan suatu tren telah dikaji oleh Mangku (2006), yang menghasilkan: 


$$
\hat{\lambda}_{n, K}(s)=\frac{\tau}{n} \sum_{k=0}^{\infty} \frac{1}{h_{n}} \int_{0}^{n} K\left(\frac{x-(s+k \tau)}{h_{n}}\right) N(d x)
$$

adalah penduga bagi $\lambda$ di titik $s \in[0, \tau)$ dengan periode ( $\tau>0$ ) diketahui (Mangku, 2006, p. 2).

Pendugaan fungsi intensitas proses Poisson periodik dengan melibatkan suatu tren linear dengan menggunakan Kernel seragam telah dibahas oleh Rachmawati (2008), yang menghasilkan:

$$
\bar{\lambda}_{c, n, b}=\frac{1-b}{(n / \tau)^{1-b}} \sum_{k=1}^{n_{\tau}} \frac{1}{k^{b}} \frac{N\left(\left[s+k \tau-h_{n}, s+k \tau+h_{n}\right]\right)}{2 h_{n}}-\frac{a(1-b)}{(n / \tau)^{1-b}} \sum_{k=1}^{n_{\tau}} \frac{(s+k \tau)^{b}}{k^{b}}
$$

adalah penduga bagi $\lambda$ di titik $s \in[0, \tau)$ dengan periode $(\tau>0)$ diketahui dan $a$ diketahui. Untuk kasus $a$ tidak diketahui diperoleh

$$
\hat{\lambda}_{c, n, b}=\frac{1-b}{(n / \tau)^{1-b}} \sum_{k=1}^{n_{\tau}} \frac{1}{k^{b}} \frac{N\left(\left[s+k \tau-h_{n}, s+k \tau+h_{n}\right]\right)}{2 h_{n}}-\hat{a}_{n, b} \frac{(1-b)}{(n / \tau)^{1-b}} \sum_{k=1}^{n_{\tau}} \frac{(s+k \tau)^{b}}{k^{b}}
$$

adalah penduga bagi $\lambda$ di titik $s \in[0, \tau)$ dengan periode $(\tau>0)$ diketahui, dengan $\hat{a}_{n, b}$ adalah penduga bagi $a$ yaitu

$$
\hat{a}_{n, b}=\frac{(1+b)}{n^{1+b}} N([0, n])-\frac{(1+b)}{n^{b}} \theta .(\text { Rachmawati, 2008, p.31). }
$$

Misalkan $N$ adalah proses Poisson homogen pada inteval $[0, \infty)$ dengan fungsi intensitas $\lambda$ yang terintegralkan lokal dan terdiri atas dua komponen, yaitu komponen periodik $\lambda_{c}(s)$ dengan periode $(\tau>0)$ diketahui dan suatu komponen tren berbentuk fungsi pangkat. Dengan kata lain untuk $s \in[0, \infty)$ fungsi intensitas $\lambda$ dapat ditulis sebagai berikut

$$
\lambda(s)=\lambda_{c}(s)+a s^{b}
$$

dengan $a s^{b}$ adalah komponen tren fungsi pangkat, $a>0$ menyatakan kemiringan dari tren, dan tulisan ini dibatasi hanya untuk $0<b<1$.

Tulisan ini tidak mengasumsikan suatu bentuk parametrik dari $\lambda_{c}$, kecuali bahwa $\lambda_{c}$ adalah periodik yaitu untuk setiap $s \in[0, \infty)$ dan $k \in \mathbb{Z}$ berlaku

$$
\lambda_{c}(s)=\lambda_{c}(s+k \tau)
$$

(Mangku, 2006,p.1). Diasumsikan bahwa $s$ adalah titik Lebesgue bagi $\lambda_{c}$, yaitu

$$
\lim _{h \rightarrow 0} \frac{1}{2 h} \int_{-h}^{h}|\lambda(x+s)-\lambda(s)| d x=0 \text {. (Mangku, 2006, p.2). }
$$

Misalkan untuk suatu $\omega \in \Omega$, hanya terdapat sebuah realisasi $N(\omega)$ dari proses Poisson $N$ yang terdefinisi pada suatu ruang peluang $(\Omega, \mathcal{F}, \mathrm{P})$ dengan fungsi intensitas seperti pada (1) yang diamati pada interval terbatas $[0, n] \in[0, \infty)$. Karena $\lambda_{c}$ adalah fungsi periodik dengan periode $\tau$, maka masalah menduga $\lambda_{c}$ pada titik $s$ dengan $s \in \mathbb{R}$ dapat direduksi menjadi masalah menduga $\lambda_{c}$ pada titik $s$ dengan $s \in[0, \tau)$ (Mangku, 2006,p.1). 
berikut:

Misalkan $K: \mathbb{R} \rightarrow \mathbb{R}$ adalah suatu fungsi bernilai real, disebut Kernel, jika memenuhi sifat-sifat (K.1) $K$ merupakan fungsi kepekatan peluang.

(K.2) $K$ terbatas.

(K.3) $K$ memiliki daerah definisi pada $[-1,1]$.

Dan $h_{n}$ adalah barisan dari bilangan real positif yang konvergen menuju nol, yaitu

$$
h_{n} \downarrow 0
$$

untuk $n \rightarrow \infty$ (Mangku, 2006, p. 2). Perlu diperhatikan bahwa, nilai asimtotik $n \rightarrow \infty$ dengan nilai $n$ bukan menyatakan ukuran sample, namun $n$ menyatakan panjang interval dari peubah acak $N([0, n])$ yang menyatakan banyaknya kejadian (Mangku, 2006, p.2).

Pada bahasan ini dikaji dua kasus, yaitu pertama diasumsikan bahwa kemiringan $a$ diketahui sedangkan fungsi $\lambda_{c}$ pada $s \in[0, \tau)$ tidak diketahui. Kedua diasumsikan fungsi intensitas global bagi $\lambda_{c}$ diketahui, sedangkan kemiringan $a$ dan fungsi $\lambda_{c}$ pada $[0, \infty)$ tidak diketahui.

\section{HASIL DAN PEMBAHASAN}

Hasil yang diperoleh pada pendugaan tipe Kernel dari $\lambda_{c}$ pada $s \in[0, \tau)$ untuk kasus $a$ diketahui, dapat dirumuskan sebagai berikut:

$$
\bar{\lambda}_{c, n, K}(s)=\frac{1}{L_{n, b} h_{n}} \sum_{k=1}^{n_{\tau}} \frac{1}{k^{b}} \int_{0}^{n} K\left(\frac{x-(s+k \tau)}{h_{n}}\right) N(d x)-\frac{a}{L_{n, b}} \sum_{k=1}^{n_{\tau}} \frac{(s+k \tau)^{b}}{k^{b}}
$$

dengan

$$
L_{n, b}=\sum_{k=1}^{n_{\tau}} \frac{1}{k^{b}}, \quad n_{\tau}=\left[\frac{n}{\tau}\right]
$$

Pembahasan mengenai penyusunan penduga tipe Kernel seperti pada persamaan (5) dapat diuraikan sebagai berikut: Pertama perlu diperhatikan bahwa, pendugaan tipe Kernel untuk fungsi intensitas proses Poisson periodik hanya didasarkan pada sebuah realisasi tunggal dari proses Poisson $N$, dengan demikian diperlukan informasi yang cukup mengenai nilai $\lambda(s)$ pada interval $[0, n]$ (Mangku, 2006, p.3). Dengan alasan ini, asumsi (2) memiliki peranan yang sangat penting dibalik penyusunan ide penduga $\bar{\lambda}_{c, n, K}(s)$ untuk $\lambda_{c}(s)$. Sehingga untuk setiap titik $s$ dan $k \in \mathbb{Z}$ dan dari (1) dan (2) maka

$$
\lambda_{c}(s)=\lambda_{c}(s+k \tau)=\lambda(s+k \tau)-a(s+k \tau)^{b} .
$$

Dengan pemisalan seperti pada (5) maka persamaan di atas menjadi

$$
\begin{aligned}
& \lambda_{c}(s)=\frac{1}{L_{n, b}} \sum_{k=1}^{n_{\tau}} \frac{1}{k^{b}}\left(\lambda(s+k \tau)-a(s+k \tau)^{b}\right) \\
& =\frac{1}{L_{n, b}} \sum_{k=1}^{n_{\tau}} \frac{1}{k^{b}} \lambda(s+k \tau)-\frac{a}{L_{n, b}} \sum_{k=1}^{n_{\tau}} \frac{(s+k \tau)^{b}}{k^{b}} .
\end{aligned}
$$


Pendekatan yang digunakan pada pendugaan fungsi intensitas lokal dari suatu proses Poisson di titik $s$ adalah dengan menaksir nilai rata-rata dari banyaknya kejadian di sekitar titik $s$. Secara matematis, misalkan $h_{n} \downarrow 0, n \rightarrow \infty$ dan $N([0, t])$ menyatakan banyaknya kejadian yang terjadi pada $[0, t]$, maka fungsi intensitas lokal di titik $s$ dapat didekati dengan

$$
\frac{1}{2 h_{n}} N\left(\left[s-h_{n}, s+h_{n}\right]\right) \text {. }
$$

Dengan demikian, nilai fungsi $\lambda(s+k \tau)$ di titik $s$ dapat didekati dengan nilai rataan dari banyaknya kejadian di sekitar $s$, yaitu pada interval $\left[s+k \tau-h_{n}, s+k \tau+h_{n}\right]$ serta dengan menggunakan (3) maka (7) dapat ditulis

$$
\bar{\lambda}_{c, n, K}(s) \approx \frac{1}{L_{n, b}} \sum_{k=1}^{n_{\tau}} \frac{1}{k^{b}} \frac{\operatorname{EN}\left(\left[s+k \tau-h_{n}, s+k \tau+h_{n}\right]\right)}{2 h_{n}}-\frac{a}{L_{n, b}} \sum_{k=1}^{n_{\tau}} \frac{(s+k \tau)^{b}}{k^{b}} .
$$

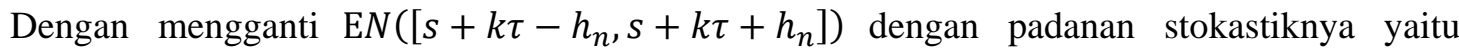
$N\left(\left[s+k \tau-h_{n}, s+k \tau+h_{n}\right]\right)$ maka (8) dapat ditulis

$$
\begin{gathered}
\bar{\lambda}_{c, n, K}(s) \approx \frac{1}{L_{n, b}} \sum_{k=1}^{n_{\tau}} \frac{1}{k^{b}} \frac{N\left(\left[s+k \tau-h_{n}, s+k \tau+h_{n}\right]\right)}{2 h_{n}}-\frac{a}{L_{n, b}} \sum_{k=1}^{n_{\tau}} \frac{(s+k \tau)^{b}}{k^{b}} \\
=\frac{1}{L_{n, b} h_{n}} \sum_{k=1}^{n_{\tau}} \frac{1}{k^{b}} \int_{0}^{n} \frac{1}{2} \mathbf{I}_{[-1,1]}\left(\left[s+k \tau-h_{n}, s+k \tau+h_{n}\right]\right) N(d x)-\frac{a}{L_{n, b}} \sum_{k=1}^{n_{\tau}} \frac{(s+k \tau)^{b}}{k^{b}} \\
=\frac{1}{L_{n, b} h_{n}} \sum_{k=1}^{n_{\tau}} \frac{1}{k^{b}} \int_{0}^{n} K_{1}\left(\frac{x-(s+k \tau)}{h_{n}}\right) N(d x)-\frac{a}{L_{n, b}} \sum_{k=1}^{n_{\tau}} \frac{(s+k \tau)^{b}}{k^{b}}
\end{gathered}
$$

dimana $K_{1}=\frac{1}{2} \mathrm{I}_{[-1,1]}$. Agar penduga yang diperoleh lebih umum maka digunakan fungsi Kernel umum $K$ sehingga diperoleh penduga bagi fungsi intensitas proses Poisson periodik untuk kasus $a$ diketahui seperti pada persamaan (5).

Selanjutnya dikaji untuk kasus $a$ tidak diketahui, pada kasus ini diperlukan penduga bagi $a$ dengan mengasumsikan bahwa fungsi intensitas global bagi $\lambda_{c}$ diketahui. Pendekatan yang digunakan pada pendugaan fungsi intensitas global dari suatu proses Poisson adalah dengan menaksir nilai ratarata dari banyaknya kejadian dalam selang $[0, n]$. Secara matematis penduga bagi fungsi intensitas global dapat dinyatakan dengan $\frac{1}{n} N([0, n])$. Dengan demikian fungsi intensitas global bagi $\lambda_{c}$ yang merupakan nilai rata-rata dari $\lambda_{c}$ pada $(0, \tau]$ yaitu $\theta=\frac{1}{\tau} \int_{0}^{\tau} \lambda_{c}(s) d s$.

Penduga dari $a$ adalah:

$$
\hat{a}_{n, b}=\frac{(1+b)}{n^{1+b}} N([0, n])-\frac{(1+b) \theta}{n^{b}} .
$$

Sehingga dapat dihasilkan penduga tipe Kernel dari $\lambda_{c}$ pada $s \in[0, \tau)$ untuk kasus $a$ tidak diketahui adalah 


$$
\hat{\lambda}_{c, n, K}(s)=\frac{1}{L_{n, b} h_{n}} \sum_{k=1}^{n_{\tau}} \frac{1}{k^{b}} \int_{0}^{n} K\left(\frac{x-(s+k \tau)}{h_{n}}\right) N(d x)-\frac{\hat{a}_{n, b}}{L_{n, b}} \sum_{k=1}^{n_{\tau}} \frac{(s+k \tau)^{b}}{k^{b}}
$$

dengan $L_{n, b}=\sum_{k=1}^{n_{\tau}} \frac{1}{k^{b}}$ dan $n_{\tau}=\left[\frac{n}{\tau}\right]$. Dapat diperhatikan bahwa persamaan (10) sama seperti pada persamaan (5) dengan mengganti nilai $a$ menjadi penduganya $\hat{a}_{n, b}$.

Untuk mendapatkan penduga $\hat{a}_{n, b}$ cukup diperhatikan bahwa

$$
\mathrm{EN}([0, n])=\int_{0}^{n} \lambda(s) d s=\int_{0}^{n} \lambda_{c}(s) d s+\int_{0}^{n} a s^{b} d s .
$$

Dengan mengganti $\mathrm{E} N([0, n])$ dengan padanan stokastiknya yaitu $N([0, n])$ maka persamaan di atas menjadi

$$
N([0, n]) \approx n \theta+\frac{a}{1+b} n^{1+b}
$$

atau dapat ditulis

$$
a \approx \frac{1+b}{n^{1+b}} N([0, n])-\frac{1+b}{n^{1+b}} n \theta .
$$

Sehingga diperoleh penduga dari $a$ yaitu $\hat{a}_{n, b}$ seperti pada (9).

\section{Lema:}

Misalkan fungsi intensitas $\lambda$ seperti (1) dan terintegralkan lokal, dengan

$$
\theta=\frac{1}{\tau} \int_{0}^{\tau} \lambda_{c}(s) d s
$$

menyatakan fungsi intensitas global bagi $\lambda_{c}$. Penduga $\hat{a}_{n, b}$ merupakan penduga yang konsisten bagi $a$, dengan Mean Square Error-nya adalah

untuk $n \rightarrow \infty$.

$$
\operatorname{MSE} \hat{a}_{n, b}=\frac{a(1+b)}{n^{1+b}}+O\left(\frac{1}{n^{1+2 b}}\right)
$$

\section{Bukti:}

Berdasarkan definisi dari $M S E$, maka

$$
\operatorname{MSE} \hat{a}_{n, b}=\left(\operatorname{Bias} \hat{a}_{n, b}\right)^{2}+\operatorname{Var} \hat{a}_{n, b}
$$

dan $\left(\text { Bias } \hat{a}_{n, b}\right)^{2}=\left(\mathrm{E} \hat{a}_{n, b}-a\right)$. E $\hat{a}_{n, b}$ dapat dihitung sebagai berikut:

$$
\begin{aligned}
\mathrm{E} \hat{a}_{n, b} & =\mathrm{E}\left(\frac{(1+b)}{n^{1+b}} N([0, n])-\frac{(1+b) \theta}{n^{b}}\right) \\
= & \frac{(1+b)}{n^{1+b}} \mathrm{EN}([0, n])-\frac{(1+b) \theta}{n^{b}} .
\end{aligned}
$$


Karena fungsi intensitas $\lambda$ seperti (1) maka persamaan diatas menjadi

$$
\begin{gathered}
\mathrm{E} \hat{a}_{n, b}=\frac{(1+b) \theta}{n^{b}}+a+O\left(\frac{1}{n^{1+b}}\right)-\frac{(1+b) \theta}{n^{b}} \\
=a+O\left(\frac{1}{n^{1+b}}\right) .
\end{gathered}
$$

untuk $n \rightarrow \infty$.

Ragam dari $\hat{a}_{n, b}$ diperoleh dengan cara yang serupa yaitu:

$$
\begin{aligned}
\operatorname{Var}_{n, b}= & \operatorname{Var}\left(\frac{(1+b)}{n^{1+b}} N([0, n])-\frac{(1+b) \theta}{n^{b}}\right) \\
= & \frac{(1+b)^{2}}{n^{2+2 b}} \operatorname{Var} N([0, n]) .
\end{aligned}
$$

Karena $N$ adalah proses Poisson, maka persamaan di atas dapat ditulis

untuk $n \rightarrow \infty$.

$$
\begin{gathered}
\operatorname{Var} \hat{a}_{n, b}=\frac{(1+b)^{2}}{n^{2+2 b}} \mathrm{E} N([0, n]) \\
=\frac{a(1+b)}{n^{1+b}}+O\left(\frac{1}{n^{1+2 b}}\right)
\end{gathered}
$$

Dengan mensubstitusikan persamaan (13) dan (14) ke (15) diperoleh

$$
\operatorname{MSE} \hat{a}_{n, b}=\frac{a(1+b)}{n^{1+b}}+O\left(\frac{1}{n^{1+2 b}}\right)
$$

untuk $n \rightarrow \infty$ seperti pada persamaan (11). Dengan demikian Lema terbukti.

\section{Teorema (Kekonsistenan $\hat{a}_{n, b}$ )}

Penduga $\hat{a}_{n, b}$ merupakan penduga konsisten bagi $a$, yaitu

$$
\hat{a}_{n, b} \stackrel{P}{\rightarrow} a
$$

untuk $n \rightarrow \infty$.

\section{Bukti:}

Berdasarkan definisi akan ditunjukkan bahwa

$$
\forall \varepsilon>0, \mathrm{P}\left(\left|\hat{a}_{n, b}-a\right|>\varepsilon\right) \rightarrow 0
$$

untuk $n \rightarrow \infty$. Berdasarkan ketaksamaan segitiga, diperoleh 


$$
\left|\hat{a}_{n, b}-a\right| \leq\left|\hat{a}_{n, b}-\mathrm{E} \hat{a}_{n, b}\right|+\left|\mathrm{E} \hat{a}_{n, b}-a\right| .
$$

Berdasarkan persamaan (13) diperoleh, E $\hat{a}_{n, b} \rightarrow a$, berarti $\forall \varepsilon>0$, ada $\mathrm{N}$ sehingga

$$
\left|\mathrm{E} \hat{a}_{n, b}-a\right|<\frac{\varepsilon}{2}, \forall n \geq \mathrm{N}
$$

Dari persamaan di atas diperoleh

$$
\mathrm{P}\left(\left|\hat{a}_{n, b}-a\right|>\varepsilon\right) \leq \mathrm{P}\left(\left|\hat{a}_{n, b}-\mathrm{E} \hat{a}_{n, b}\right|>\frac{\varepsilon}{2}\right)
$$

Jadi untuk membuktikan (15) cukup ditunjukkan

$$
\mathrm{P}\left(\left|\hat{a}_{n, b}-\mathrm{E} \hat{a}_{n, b}\right|>\frac{\varepsilon}{2}\right) \rightarrow 0 .
$$

Dengan ketaksamaan Chebychev, diperoleh

$$
\mathrm{P}\left(\left|\hat{a}_{n, b}-\mathrm{E} \hat{a}_{n, b}\right|>\frac{\varepsilon}{2}\right) \leq \frac{4 \operatorname{Var} \hat{a}_{n, b}}{\varepsilon^{2}} .
$$

Dari persamaan (14) diperoleh Vara $\hat{a}_{n, b} \rightarrow 0$ untuk $n \rightarrow \infty$, sehingga diperoleh (16). Dengan demikian Teorema terbukti.

Selanjutnya, pembahasan mengenai ide pembentukan penduga $\hat{\lambda}_{c, n, K}(s)$ bagi $\lambda_{c}(s)$ untuk kasus $a$ tidak diketahui sama dengan kasus $a$ diketahui, yaitu dengan mengganti $a$ pada kasus pertama dengan $\hat{a}_{n, b}$. Sehingga hasil dari pendugaan $\hat{\lambda}_{c, n, K}(s)$ pada kasus ini adalah:

$$
\hat{\lambda}_{c, n, K}(s)=\frac{1}{L_{n, b} h_{n}} \sum_{k=1}^{n_{\tau}} \frac{1}{k^{b}} \int_{0}^{n} K\left(\frac{x-(s+k \tau)}{h_{n}}\right) N(d x)-\frac{\hat{a}_{n, b}}{L_{n, b}} \sum_{k=1}^{n_{\tau}} \frac{(s+k \tau)^{b}}{k^{b}}
$$

dengan memisalkan $L_{n, b}=\sum_{k=1}^{n_{\tau}} \frac{1}{k^{b}}$ dan $n_{\tau}=\left[\frac{n}{\tau}\right]$, $\hat{a}_{n, b}$ adalah penduga bagi $a, K$ adalah suatu Kernel, dan $h_{n}$ adalah barisan bilangan real positif yang konvergen menuju nol, yaitu $h_{n} \downarrow 0$ untuk $n \rightarrow \infty$.

\section{PENUTUP}

Dari kajian yang telah dilakukan, diperoleh:

Penduga tipe Kernel bagi $\lambda_{c}$ pada $s \in[0, \tau)$ untuk kasus $a$ diketahui adalah:

$$
\bar{\lambda}_{c, n, K}(s)=\frac{1}{L_{n, b} h_{n}} \sum_{k=1}^{n_{\tau}} \frac{1}{k^{b}} \int_{0}^{n} K\left(\frac{x-(s+k \tau)}{h_{n}}\right) N(d x)-\frac{a}{L_{n, b}} \sum_{k=1}^{n_{\tau}} \frac{(s+k \tau)^{b}}{k^{b}}
$$

dengan $n$ adalah panjang interval pengamatan, $n_{\tau}=\left[\frac{n}{\tau}\right], L_{n, b}=\sum_{k=1}^{n_{\tau}} \frac{1}{k^{b}}, K$ adalah suatu Kernel, dan $h_{n}$ adalah barisan bilangan real positif yang konvergen menuju nol, yaitu $h_{n} \downarrow 0$ untuk $n \rightarrow \infty$.

Penduga tipe Kernel bagi $\lambda_{c}$ pada $s \in[0, \tau)$ untuk kasus $a$ tidak diketahui adalah: 


$$
\hat{\lambda}_{c, n, K}(s)=\frac{1}{L_{n, b} h_{n}} \sum_{k=1}^{n_{\tau}} \frac{1}{k^{b}} \int_{0}^{n} K\left(\frac{x-(s+k \tau)}{h_{n}}\right) N(d x)-\frac{\hat{a}_{n, b}}{L_{n, b}} \sum_{k=1}^{n_{\tau}} \frac{(s+k \tau)^{b}}{k^{b}}
$$

dengan $n$ adalah panjang interval pengamatan, $n_{\tau}=\left[\frac{n}{\tau}\right], L_{n, b}=\sum_{k=1}^{n_{\tau}} \frac{1}{k^{b}}, K$ adalah suatu Kernel, dan $h_{n}$ adalah barisan bilangan real positif yang konvergen menuju nol, yaitu $h_{n} \downarrow 0$ untuk $n \rightarrow \infty$, serta

$$
\hat{a}_{n, b}=\frac{(1+b)}{n^{1+b}} N([0, n])-\frac{(1+b) \theta}{n^{b}}
$$

adalah penduga konsisten bagi $a$.

Penduga $\hat{a}_{n, b}$ merupakan penduga yang konsisten bagi $a$, dengan Mean Square Error-nya adalah

$$
\operatorname{MSE} \hat{a}_{n, b}=\frac{a(1+b)}{n^{1+b}}+O\left(\frac{1}{n^{1+2 b}}\right)
$$

untuk $n \rightarrow \infty$, dan fungsi intensitas $\lambda$ seperti (1) dan terintegralkan lokal, dengan

$$
\theta=\frac{1}{\tau} \int_{0}^{\tau} \lambda_{c}(s) d s
$$

menyatakan fungsi intensitas global bagi $\lambda_{c}$.

\section{DAFTAR PUSTAKA}

Ghahramani, S. (2005). Fundamental of Probability, ( $3^{\text {rd }}$ ed.). New York: Prentice Hall.

Hogg, R. V. \& Craig, A. T. (2005). Introduction to Mathematical Statistics, (5th ed.). New Jersey: Prentice Hall, Engelwood Cliffs.

Mangku, I. W. (2001). Estimating the Intensity of a Cyclic Poisson Process. Amsterdam: University of Amsterdam.

Mangku, I. W. (2006). Asymptotic Normality of a Kernel-type Estimator for the Intensity of a Periodic Poisson Process. Journal of Mathematics and Its Applications, 5 (2), 13-22.

Mangku, I. W. (2006). Weak and Strong Convergence of a Kernel-type Estimator for the Intensity of a Periodic Poisson Process. Journal of Mathematics and Its Applications, 5 (1), 1-12

Rachmawati, N. R. (2008). Sifat-sifat Statistika Penduga Fungsi Intensitas Proses Poisson Periodik dengan Tren Fungsi Pangkat. Skripsi tidak diterbitkan. Bogor: Fakultas Matematika dan Ilmu Pengetahuan Alam Institut Pertanian Bogor.

Wheeden, R. L., Zygmund, A. (1997). Measure and Integral: An Introduction to Real Analysis. New York: Marcell Dekker. 